\title{
A arte e a psicanálise e a psicose: seriam as criações um possível lugar de inscrições?
}

\author{
Art and psychoanalysis and psychosis: are creations \\ a possible place of registration?
}

\section{Bárbara de Castro Gonçalves}

\begin{abstract}
Resumo: Partindo do trabalho da autora dentro de um hospital psiquiátrico de internação masculina e psicoses severas, o objetivo da presente pesquisa é trazer à discussão, a partir da abordagem psicanalítica, de que forma as criações artísticas seriam um possível lugar de inscrições para estabilização da estrutura psicótica. Para tal efeito, revisou-se os conceitos que explanam a condição estruturante do sujeito, historicizando a importância da arte interface à neurose e à psicose, e colocando em relevo a ética da psicanálise que contrapõe a prática normativa. Nesse percurso, chegou-se à conclusão que o uso de dispositivos artísticos como possíveis recursos para o suporte clínico, podem colocar-se também como uma estratégia potencializadora no processo de constituição enunciativa, dando um contorno estético ao excesso de gozo, possibilitando um arranjo de inscrição e ressituando o sujeito psicótico no enlaçamento social.
\end{abstract}

Palavras-chave: Psicanálise; Psicose; Arte; Estabilização Psicótica.
Abstract: Starting from the author's work inside a psychiatric hospital with male hospitalization and severe psychoses, the objective of this research is to bring to the discussion, from the psychoanalytical approach, how the artistic creations would be a possible place of inscriptions for stabilization of the psychotic structure. To this end, the concepts that explain the structuring condition of the subject were reviewed, historicizing the importance of interface art to neurosis and psychosis, and emphasizing the ethics of psychoanalysis that opposes normative practice. In this way, it was concluded that the use of artistic devices as possible resources for clinical support can also be placed as a potentializing strategy in the process of enunciative constitution, giving an aesthetic contour to the excess of enjoyment, allowing an arrangement of inscription and resituating the psychotic subject in the social bond.

Keywords: Psychoanalysis; Psychosis; Art; Psychotic stabilization.

\footnotetext{
1 Graduada em Psicologia pela Faculdade São Francisco de Assis. E-mail: barbaradecastro2010@hotmail.com .
} 


\section{Introdução}

Ao propor uma investigação que contemple a arte $e$ a psicanálise $e$ a psicose, ressalta-se, primeiramente, a conjunção aditiva e para explicar que não se trata de um equívoco gramatical ou de um simples detalhe, mas sim, seu significado por excelência: conectar orações sem disso fazer uma fusão. É no intuito de aproximar esses três campos que esse debate se faz valer, impulsionado pela vivência da autora ao estagiar em um hospital psiquiátrico, dentro de uma unidade de internação masculina de psicoses severas, provocando assim conhecer, através de uma pergunta-constatação, como os recursos provenientes das criações artísticas são capazes de produzir inscrições psíquicas que possam ensaiar uma estabilização ou dar uma ancoragem ao funcionamento psicótico, sustentando a hipótese da presença de um sujeito nesta estrutura.

No que diz respeito à metodologia adotada na realização desta pesquisa, de abordagem qualitativa e caráter exploratório, torna-se nítido que a ideia não foi esgotar a bibliografia sobre 0 assunto, mas pontuar algumas obras expoentes sobre o tema: a própria investigação psicanalítica já parte do princípio da inverossimilhança de uma sistematização completa e exclusiva, justamente por trabalhar com a impossibilidade da previsão do inconsciente. A coleta de dados deu-se através de fontes bibliográficas de livros impressos, artigos científicos e teses de corrente psicanalítica relacionadas ao tema, articulados às reflexões experenciadas da própria autora em seu estágio de psicopatologia, através da observação, da inferência e do manejo clínico. Nas explanações de Ravasio (2016), "a pesquisa psicanalítica é sempre uma apropriação do autor, que depois de estudar e ter um enigma, uma pergunta, filia-se a essa vertente e a singulariza na realização de uma pesquisa." (p.3).

Os tempos que despontam, sempre convocam novos diálogos frente às configurações que emergem: a cultura se modifica, as famílias se transformam, e o sofrimento psíquico, tão influenciado pelo contexto daquilo que se vive, também fala de outras formas de se dar. Para isso, a psicanálise, que jamais está findada, convoca àqueles que a seguem a não se acomodarem. Por seu turno, Freud (1969c) já havia deixado o mundo ocidental atônito ao revelar que o homem não era o senhor de sua própria morada (nele habitavam forças que ele próprio desconhecia), e com seu pensamento híbrido sistematizou a metapsicologia, trazendo à baila o inconsciente como uma outra cena, a sexualidade infantil, a neurose como normalidade. Seu predecessor, Lacan, outro expoente da psicanálise, surge embebido da influência surrealista, estruturalista e lingüística, e através da complexidade de sua obra, vem falar do inconsciente estruturado como uma linguagem - há uma primazia do significante. Ocorre que, ambos não morreram sem perceber as incertezas e hesitações de suas teorizações, e aí está, porque não dizer, a própria arte do saber-fazer do psicanalista: andar no fio da navalha entre a tensão do sempre necessário rigor teórico e as novas formas de enfrentar as problemáticas contemporâneas que constantemente convocam e exigem diferentes dispositivos de tratamento, e que não se limitam ao discurso binário de saúde-doença.

0 presente artigo não foge a esse apelo, e parte da investigação dos conceitos fundantes da estruturação do psiquismo, delineando suas principais características, funcionamentos e defesas. Nesse contexto, serão explanadas tais premissas a partir do referencial freudiano, em que o indivíduo, diante da angústia da castração, cria soluções de defesa, resultando irreversivelmente na constituição da neurose, da psicose ou da perversão. Paralelamente, serão deslindados alguns pressupostos lacanianos, que em seu retorno ao pensamento de Freud, propôs que a forma de o sujeito se situar na linguagem, será organizadora de toda sua existência.

Em um segundo momento, a proposta será discutir a importância da arte para psicanálise, interface à neurose e à psicose, colocando em relevo as diferenças dos efeitos da criação artística para ambas estruturas, situando que, na neurose, existe um sujeito implicado ao ato que produz a obra - há algo do seu psiquismo que ali comparece e é fruto da passagem entre o excesso pulsional e a cultura, no processo de sublimação. Já na psicose, as criações artísticas, além de promotoras de significação, seriam também localizadoras de gozo (dentro ou fora do corpo), auxiliando o sujeito psicótico a tecer um gradil capaz de ordenar as suas experiências, produzindo-Ihe marcas que possam arranjar alguma ordenação lógica de significantes soltos, proporcionando ainda, um possível ensaio de enlaçamento com o social.

A última explanação dará contorno a ética da psicanálise e seu entendimento de cura, onde a aposta do técnico deve se dar na expressão da singularidade do sujeito, e não fundamentada pela satisfação do profissional que o acompanha - este deve pautar seu trabalho na especificidade de cada indivíduo, mobilizando o que há de particular em sua vida, contrapondo as formas de tratamentos normatizantes e serialistas, jamais impondo o recurso de criação como uma atividade obrigatória à terapêutica, o que acarretaria em uma psicologização da arte.

Por fim, é preciso salientar que a arte e a psicanálise e a psicose sempre comungaram de um certo distanciamento e da oposição a determinados saberes tradicionais e adaptativos que hegemonizam o coletivo - idiossincráticas, há algo em ambas que é da ordem do indecifrável...e, em algum momento de sua história, desconfiaram da razão.

\section{A condição estruturante do sujeito: a psicose à luz da teoria psicanalítica}

Considerando a clínica estrutural, a neurose ${ }^{2}$, a perversão ${ }^{3}$ e a psicose ${ }^{4}$, são as possíveis saídas do complexo de Édipo - sua forma de lidar com a castração em uma operação de defesa, no sentido freudiano. Em seu retorno à Freud, Lacan (1984), revitalizou o conceito de inconsciente, dizendo que este tem sua própria gramática e lógica, onde as estruturas se colocam como um modo de estar na linguagem, em uma teia de significantes que vão estabelecendo-se e engendrando-se concomitantemente a uma economia psíquica das forças pulsionais. Através da posição ocupada frente ao falo na travessia edipiana, a criança se defende de ser reduzida a objeto de uma demanda imaginária do Outro (Calligaris, 1989), desembocando ou não, a sua inserção na ordem simbólica. Uma vez efetivada sua inscrição na linguagem, o infante se firma como desejante pela via da palavra, logo, a estruturação do

\footnotetext{
2 A representação da castração é insuportável, logo, o elemento traumático (a falta no outro) é negado no nível do simbólico, mas acaba retornando no próprio simbólico do sujeito.

3 O elemento traumático é desmentido: a percepção da castração permanece, porém, é contestada transformando-se o falo faltante do Outro em fetiche, que é seu representante simbólico.

${ }^{4}$ O significante primordial não representa a castração e essa acaba por não se inscrever no simbólico. Este significante da castração no Outro, o Nome-do-Pai, é foracluído do simbólico e retorna no real.
} 
sujeito psíquico vai ser definida sempre como uma resposta do real à falta, na dialética desejo-lei à metáfora paterna.

No âmbito de sua teoria do significante e de sua tópica (imaginário, real e simbólico), ele (Lacan) definiu o complexo de Édipo como uma função simbólica: o pai intervém sob a forma da lei, para privar a criança da fusão com a mãe. Segundo essa perspectiva, o mito edipiano atribui ao pai, por conseguinte, a exigência da castração: a Lei primordial (Roudinesco e Plon, 1998, p. 182).

Quando o significante do Nome-do-Pai, representante da Lei, é foracluído e, portanto, não capaz de barrar o desejo materno, o efeito será a instauração da psicose (Lacan, 2005b). Logo, a verwerfung, a foraclusão, este rechaço do simbólico que implica o surgimento de algo na ordem do real, é a maneira defensiva que o indivíduo arma para lidar com a falta: ocorre uma ruptura com a realidade extrínseca, instaurando-se assim uma hiância, e é justamente aquilo que foi posto para fora da simbolização que retorna desde este exterior. Uma vez não submetido à castração simbólica, todo processo de recalcamento é comprometido, e, conseqüentemente, a própria estruturação como sujeito desejante.

Se a inscrição norteadora que amarra, organiza a estrutura do sujeito e decide todas as demais significações está ausente, o sujeito permanece à margem do discurso, do laço social, e o faz circular de forma diferente nas significações da cultura, esteja ele em crise ou fora dela. Segundo Coriat (1997) para o psicótico"não há falta porque nada foi perdido e nada foi radicalmente proibido." (p. 237). Ele éo que o Outro diz que eleé, permanecendo inteiramente subjugado a este Outro que pode colocar-se de forma cabalmente invasiva, principalmente nos momentos de crise aguda. Ainda que sua linguagem tenha certa articulação lógica, nem por isso ela é reconhecida, seu efeito é de um estranhamento, como se o interlocutor ignorasse a própria língua falada:

[...] não podemos pensar que ele esteja tomado nos registros Imaginário e Real somente. Por que ele tem indubitavelmente uma significação de sujeito. Ele está tomado numa articulação simbólica, chega a circular nesse registro. Mas, se está tomado numa articulação simbólica, está tomado certamente de um jeito diferente do que um neurótico. (Calligaris, 1989, p.13)

Sabe-se quem nem mesmo a inscrição do Nome-do-Pai dá ao sujeito garantias de a tudo significar - sua relevância está em permitir um ingresso à linguagem, entretanto, sem efetivamente responder ao enigma do desejo materno. 0 principal efeito da operação da metáfora paterna é a lógica fálica, que sentencia o sujeito neurótico a permanecer dando voltas ao redor de um centro único: o falo, que é simbólico, mediador de todas as coisas, e que também é imaginário, sempre apontando para o desejo inalcançável. Mas se o psicótico se situa fora dessa premissa, é este ser não-barrado e eminentemente propenso à errância uma vez que há um horizonte de significações sem polo mediador, deixá-lo à mercê de um tratamento pautado somente pela fenomenologia descritiva de sinais e sintomas, é permitir que ele permaneça, ainda, no hiato de sua existência.

\section{É possível dizer sem palavras?}

Mais de um século atravessado pela psicanálise, em que ela se debruçou sobre a questão da psicose, e ainda seguem os empecilhos impostos pela clínica, seja no manejo da transferência ou na inviabilidade de metaforização. $\mathrm{Na}$ teoria lacaniana, a estabilidade dessa estrutura se dá por mecanismos imaginários, logo, a direção de sua clínica precisa ofertar múltiplas alternativas dentro do enquadre psicanalíico, que proporcionem al guma ancoragem a sua estrutura - não para mudá-la, mas para mudar as relações entre os seus elementos (Balbo e Berges, 2003). Se para Descartes (2001) a verdade habitava a consciência do sujeito cartesiano, contrapondo a filosofia escolástica ${ }^{5}$ com o ergo sum ${ }^{6}$, Freud subverteu esse axioma apontando a psicanálise como a terceira grande ferida narcísica sofrida pelo saber ocidental ao produzir um descentramento da razão, rompendo com a definição iluminista do sujeito da vontade: a consciência passa ser o lugar da mentira, do ocultamento, da distorção e da ilusão. 0 estilo gongórico lacaniano também contrapôs o cogito de res cogitans ${ }^{7}$ com seu célebre aforismo "penso aonde não sou, sou onde não penso" (Lacan, 1998, p. 521).

A epistemologia e o desenvolvimento da psicanálise se dão na escuta e a partir da escuta singular à qual se compromete, onde a palavra, veículo de acesso ao inconsciente, dentro da metapsicologia inaugurada por Freud, torna-se a pedra angular do tratamento analítico, e através de sua técnica traz à cena o discurso secreto sobre o sujeito: é justamente onde o sujeito hesita, naquilo que não Ihe surge palavras, no branco do pensamento, que está o plano do inconsciente. Na psicose, por mais atrapalhada que a fala possa parecer, devido as suas problematizações nas leis da linguagem, sem amarramento semântico e enunciativo, é preciso acolhê-la. Para Lacet (2004), há frases interrompidas, neologismos, reiteração de letras, maneirismos, verborragias e relações cabalísticas, e assim, na ausência de metáfora e diante das poucas possibilidades de representação, alguns casos podem resultar em narrativas empobrecidas, cristalizadas e repetitivas - aquilo que o neurótico é capaz de elaborar pela associação livre, pelo ato falho, pelo chiste, no psicótico, torna-se concreto, literal, colado ao discurso do Outro. A linguagem consegue permanecer no silogismo, entretanto, sem qualquer sistematização por trás desta: resta somente a convicção da evidência.

Na loucura [.. . ] convém reconhecermos [... ] a liberdade negativa de uma fala que renunciou a se fazer reconhecer, ou seja, aquilo que chamamos obstáculo à transferência, e [... ] a formação singular de um delírio que [.. . ] objetiva o sujeito em uma linguagem sem dialética (Lacan, 1984, p. 281).

\footnotetext{
${ }_{5}^{5}$ Conjunto de pensamentos originais desenvolvidos nas universidades da Europa Ocidental, especialmente durante a Baixa Idade Média.

6 "Penso, portanto, sou", popularmente traduzida para o português como "penso, logo existo".

7 O pensamento como única garantia de existência.
} 
0 neurótico, ao falar, busca ser reconhecido, fazendo um apelo para que o Outro o compreenda, mas o psicótico não está interessado nisso - ele goza de seu próprio falatório estéril e parodiado. Se o sujeito psicótico é então esse louco que, diferentemente de outros, não se defende do real pelo simbólico, não se alienando, portanto, nas palavras (Leite, 2007), é preciso viabilizar estratégias outras de trabalho para auxiliar o sujeito em uma sutura do seu enodoamento borromeano, em que o campo de ação da psicanálise - a palavra - teça aliança com outras possíveis ferramentas para (re)criar ou (re) construir aquilo que falha na simbolização. Nessa ausência é preciso, como disse Lacan (1985), o uso de muletas imaginárias para que o sujeito possa estar no mundo. Dito de uma outra forma, trata-se de um remendo de linguagem, um rearranjo para expressar o que lhe ocorre, uma vez que o psicótico está fora do código linguageiro. Segundo Melman (1991), a fala do psicótico é livre de todo recalcamento, revelando um inconsciente do qual ele não se defende, sem ponto de estofo ${ }^{8}$ amarrado pelo significante primordial.

Escutar o dito e o não dito, é sempre permitir-se ouvir as entrelinhas, apostando em alguma possibilidade enunciativa, em que o interlocutor se mantém aberto à surpresa e ao imprevisto. Para Silva (2001), o dizer produzido pelo sujeito psicótico pode ser realmente"vazio, estereotipado, mas ele pode se exprimir, talvez até de uma forma extraordinária, num outro nível, que é não-equivalente, mas uma outra forma de expressão, de mesmo valor que o discurso falado." (p.100).

\section{A arte e a psicanálise: tencionando os códigos instituídos em busca de outras significações}

A corrente psicanalítica sempre demonstrou interesse pelas origens e mistérios enredados no processo artístico. Desde as primeiras concepções freudianas sobre o inconsciente e o complexo de Édipo, inspiradas em Shakespeare e na tragédia de Sófocles, as artes marcavam presença e sinalizavam os caminhos que estariam por vir. Nessa esteira de pensamentos, a arte foi um dos solos sobre o qual a psicanálise celeremente exerceu influência:

Havia uma forte ressonância entre as ideias modernas da arte e o pensamento psicanalítico, ambos surgidos de um terreno comum e construídos em torno de uma concepção de subjetividade bastante próxima, no centro da qual está o inconsciente que se revelaria em palavras, em sonhos e em obras, por intermédio da linguagem. (Lima , 2009, p.77).

Essa aproximação não se dá somente por seu valor estético, mas como uma das formas de lidar com o vazio, em torno da Coisa, das Ding ${ }^{9}$ (Lacan, 1997), que auxilia o sujeito na invenção de um modo de estabelecer seu contorno singular em torno desse furo. A obra de arte figura um movimento subjetivo e, segundo a abordagem lacaniana, seria uma articulação discursiva apta a salvaguardar justamente o vazio da Coisa: deslocando-se do plano da fantasia e circulando pelo real que encalça o sujeito.
A arte (assim como a psicanálise) reluzirá sempre 0 esplendor do objeto perdido e ocultará o seu mistério indevassável, mítico, e resistirá num casulo, num núcleo inacessível a quaisquer interpretações de sentido e, espero, a qual quer tentativa de devastação por parte do próprio homem, seu criador. Ela impulsionará, silenciosa, 0 arco e flecha de Eros, a fisgar e enlaçar humanos, erótica e afetivamente, criando vínculos sociais, civilizatórios e éticos. Se exibe, despida sob véus, para ser usufruída, fruída em seu charme e fascínio encantatórios, sem nunca se tornar totalmente compreendida, explicada ou devassada. (Morais, 2006, p. 55).

Foi justamente no decorrer da construção do edifício psicanalítico que os estudos rigorosos de Freud, por vezes encontraram na arte uma companhia, seja na literatura, na escultura ou na poesia. Através da análise clínica-teórica de artistas $^{10}$ e suas obras, o pai da psicanálise outorgou testemunho de sua tese sobre o inconsciente: sempre há um sujeito implicado no ato que produz a obra, e portanto, um saber, cujo estatuto é sempre insabido.

A arte é descrita na neurose como um dos destinos da pulsão pela via da sublimação, através de uma ordem já estabelecida culturalmente e dentro de uma lógica simbólica, onde 0 artista busca na obra aquilo que sobrou do seu gozo desaparecido por estar inscrito na filiação. Freud (1969b), postula que, em ambas estruturas - neurose e psicose - há um certo abrandamento da realidade, de alguma forma o sujeito dela se anestesia, e o que está em jogo é justamente o que irá ser utilizado para essa substituição: na neurose, é a fantasia quem ocupa-se desse papel, e na psicose, a alucinação e o delírio ${ }^{11}$ - as elaborações de defesa perante aquilo que é impossível de representação pela linguagem. Nas palavras genuínas de Clarice Lispector (1980) ao dizer "não quero ter a terrível limitação de quem vive apenas do que é passível de fazer sentido. Eu não: quero é uma verdade inventada" (p.22), demarca-se com a sensibilidade e a precisão dos grandes poetas - aquilo que todos estão sempre a se perguntar: o que é, afinal, possível de se representar?

Enquanto fonte de expressão inconsciente, a arte possibilita ao artífice, por intermédio da sua obra, exprimir sua forma de relacionar-se com a sua realidade psíquica, que sempre é decisiva: é a fantasia que se manifesta, que traz notícias do inexprimível, do desejo arcaico, e que agora surge envolto de forma plástica, estética, ganhando representação no status de obra. Para Freud (1969a), "toda fantasia é a realização de um desejo, uma correção da realidade insatisfeita" (p.152), sendo assim, a fantasia do artista ilusoriamente atua para fazer um contorno ao seu recalque, dando vazão a o excesso pulsional através da criação artística - um destino sublimatório que ganha o apreço do outro, uma vez que este, inconscientemente, se identifica com a sua própria abnegação do princípio do prazer: "em que esse'dar-a-ver'apazigua algo? — Senão pelo fato de que há um apetite do olho naquele que olha. Esse apetite do olho que se trata de nutrir constitui o valor do charme da pintura."(Lacan, 1964, p.131).

Para a psicanálise, da mesma forma como ocorrem nos sonhos e nos sintomas, a criação artística é uma forma de resposta às exigências pulsionais, e nessa trilha reflexiva, 0 artífice é um indivíduo marcado e movido pela

\footnotetext{
8 Ponto de capiton: organizador da cadeia de significantes que remete à filiação.

9 Aquilo "que do real padece do significante" (LACAN, 1958-1959, p.152)

10 Leonardo da Vinci e uma lembrança de sua infância (1910) e Moisés de Michelangelo (1914), por exemplo.

11 Efeito imaginário produzido a partir da emergência da falta (não se trata de uma manifestação inconsciente).
} 
insatisfação: há algo que o indicia e ele age por aí. Segundo Souza (2014), a arte" instaura desordem, funda um fora de lugar, cria uma espécie de colapso no sujeito, lembrando que o desafio do artista (e também do psicanalista), é de encontrar o corte certo entre estrutura e colapso." (p.3).

\section{Entre os excessos e as insuficiências nas psicoses, o que podem os recursos artísticos?}

A prática clínica com psicóticos é sempre confrontada pelo impacto da impossibilidade de representação que assola esses sujeitos, tornando a comunicação difícil e prejudicada. Na psicose, o sujeito psíquico está a esmo e 0 ato de criar pode então tomar forma de um ensaio de inscrição, possibilitando sair do vazio da significação. Quinet (2006), diz que a obra de arte na psicose tem como função "servir de pasto ao olhar sedento do Outro que visa o ser do sujeito, fixando na obra e, portanto, desviando de si, o olhar mortífero do Outro" (p. 218). É Lacan (1992) quem nos convoca a agir e pensar formas de trabalho ao dizer que não se deve recuar diante da psicose. Além da metáfora delirante (de constituição imaginária), e da emergência do sinthoma (em que ocorre a junção do simbólico com o real), pode colocar-se como uma possibilidade de pontos de estabilização dessa estrutura a arte, sendo esta capaz de ocupar uma posição de juntura, fazendo um arranjo reparador do nó que ata e organiza a experiência subjetiva.

Concebê-los como capazes de construir respostas, implica deslocá-los de uma posição de deficitários, infantilizados, incapazes, para a de sujeitos responsáveis pelas produções que realizam, sejam elas delírios, atos, obras ou outras. Assim, qualquer processo reabilitador só se reveste de interesse na medida em que respeita 0 estilo do sujeito para o qual se aplica, acompanhando seus movimentos subjetivos e suas possíveis formas de enlaçamento social (Guerra et al., 2006, p. 31).

Seja fora de crise (onde o sujeito consegue se relacionar consigo próprio e com o mundo por uma ortopedia imaginária) ou imerso nela (quando 0 psicótico tropeça no vão, no buraco da significação absorta), as criações podem restituir ao sujeito alguma significação: a potência artística e criativa oferece continência aos impulsos anacrônicos, às intensidades, estreitando assim, os laços com a realidade externa, conforme refere a teoria winnicottiana. Para esse autor, a psicose é compreendida como "uma doença de deficiência do ambiente" (Winnicott, 1983, p.231), efeito de determinados equívocos de construção da personalidade, no processo de amadurecimento pessoal, onde 0 ambiente não foi facilitador o suficiente e causou marcas permanentes de pânico e aniquilamento no sujeito. A arte então propõe saídas inventivas aos conflitos psíquicos, pois na relação com os objetos transicionais, o sujeito pode manter seu encontro com o verdadeiro self: este objeto, segundo Winnicott (1975), surge na brincadeira em uma zona intermediária entre o dentro e 0 fora, a legítima matriz da experiência cultural, isolando o que subjetivamente se percebe daquilo que é concebido de forma objetiva. É justamente nesse espaço intermediário, de passagem, que ocorre um processo de diferenciação entre o meio psíquico interno e o ambiente externo. Cria-se assim, uma área de ilusão, que na criança manifesta-se no lúdico e no adulto, na arte (Winnicott, 1975). Esse jogo de sincronicidade da relação entre dentro e fora, entre eu e outro, evidencia a questão do corpo: sabe-se que na psicose, o corpo não énem unificado, nem próprio - ele continua como uma extensão, um complemento do corpo de um outro especular.

Pankow (1989), psicanalista que também se dedica ao estudo das psicoses, trabalhou em uma perspectiva de oferecer ao sujeito outras formas de sensações corporais táteis na intenção de conduzi-lo a reconhecer os limites de seu próprio corpo, onde a arte entra como um recurso mediador fazendo com que o corpo não seja totalmente invadido pelo Outro. De qualquer maneira, o corpo é referenciado como lugar no qual as experiências subjetivas podem ser comunicadas de forma individual, próprias de cada um, por isso Calligaris (2004) afirma que a psicanálise não é atacadista, ela trabalha no varejo: 0 desejo e a fantasia só obtêm seu sentido nas vidas singulares. Forjada nesse embasamento, é que Neubarth (2009), ao trabalhar com pacientes psicóticos em oficinas de criatividade de um hospital psiquiátrico, demarcou sua prática na singularização e também na inclusão, sempre certificando a eles, possibilidades:

Assim, na leitura daquele pedaço de mundo, persegui com afinco a viabilização daquelas pessoas. Observando-os em suas pequenas descobertas, suas conquistas, em algum traço peculiar, um brilho no olhar, um afago, e, até, nas suas bizarrices, nas manhas ou nas chatices. Enfim busquei conhecê-los no seu jeito de ser e estar no mundo, em suas diferenças, naquilo que, tirando-os do anonimato, Ihes dava um lugar de sujeito (Neubarth, 2009, p. 26).

Aquilo que é singular de cada sujeito, ainda que identificados em uma mesma estrutura clínica, é a tônica da vertente psicanalítica. Mas se o psicótico se encontra fragilmente estruturado fora do discurso, ele necessita, de alguma forma, de uma significação subjetiva. Posto isso, aquilo que ele cria artisticamente, produz um objeto de gozo separado de si - fora do corpo (no caso da esquizofrenia) ou fora do campo do Outro (no caso da paranóia), onde o sujeito pode inventar as suplências necessárias para reconstrução de sentidos, para reedificar a realidade que rejeitou, e em ambas situações, emerge qualquer coisa remetida a um outro, sinalizando assim, algo próximo a um laço social.

Para Goidanich (2004), o ato criativo pode ser visto como "aquele movimento que estabelece algum corte, que desenha uma borda, que instituiu um contorno, delimita uma fronteira." (p.106). A criações materiais, que abrangem todo leque do campo plástico-visual, surgem como possibilidades de o sujeito lidar com as excitações mentais e corpóreas que lhe importunam e atélhe aniquilam, e de singularmente manifestar-se, dizer-se. Para algumas psicanalistas como Mannoni (1999) e Dolto (1984), os desenhos se colocam como uma alternativa do sujeito falar de si, não como o interino da palavra, mas como um suporte para evocá-la.

Segundo Read (1983), a "psique fragmentada também deve ser reconstruída e a terapia criativa - a que chamamos arte - oferecesse essa possibilidade." (p.15). Reiterando essa alegação, para Silva e Alencar (2009), aquilo o que for produzido pelo sujeito psicótico poderá estar conexo com 0 seu trabalho psíquico, e isto "é mais importante do que a aceitação social de sua produção, no sentido estético, ou seja, o importante é que essa produção possa fixar um lugar para seu inventor." (p.6). 
Utilizando-se dos elementos que o psicótico traz, o analista deve escutar qual a saída que cada sujeito aponta como sendo aquela que the é possível. Há aqueles que podem fazer uma suplência pela escrita, pela arte, pela identificação(...) o que está em jogo na psicose é"0 que pode o sujeito" (Ferreira e Trópia, 2000, p. 148).

Na psicose, o sujeito, sem guia central, percorre todos os caminhos. No manejo clínico, as criações artísticas são processuais e podem estabelecer uma temporalidade, como coordenadas simbólicas que norteiam o psiquismo à deriva, contabilizando e cifrando o gozo, em uma tentativa de se descolar da posição de objeto do Outro.

Os sujeitos psicóticos precisam envolver-se de algum modo com o princípio e o fim das coisas. E se é justamente os começos e os fins das coisas que não podem ser prontamente simbolizados, usando uma grade de significação preexistente, o sujeito psicótico precisa reinventar. Esse ato pode incluir a fala, mas implica também uma criação material: escrever, desenhar, pintar, esculpir ou qualquer prática humana de cunhagem ou inscrição (Leader, 2011, p.364).

0 indizível emerge quando o psicótico escreve com a cor, pinta com 0 cheiro, molda com o som - sem recalcamento, tudo está a flor da pele: se a palavra não lhe chega, o sujeito pode fazer com ela. Na letra escrita, na modelagem da peça, na pincelada de tinta, marcas se produzem no papel, na argila, na tela...e se a isso pudessem ser somadas palavras que endereçassem um sentido? Não seria possível, utilizar-se das marcas materialmente registradas para construir também algumas formas de inscrições psíquicas que promovessem uma certa significação, localizando a libido e permitindo uma distância segura do Outro? 0 dispositivo da arte propicia ao sujeito psicótico formas de lidar com os excessos pulsionais e com a insuficiência da ordenação subjetiva, em um fazer criativo que favorece um trabalho ao nível da articulação significante.

\section{A ética da psicanálise: a dimensão intersubjetiva que sustenta o lugar do sujeito}

Lacan (1997), ao legitimar que "toda verdade tem uma estrutura de ficção"(p.22), foi taxativo no que se refere à questão da ética da psicanálise: nem a veracidade sintomática do sujeito neurótico ou delirante do psicótico, e tão pouco a austeridade científica, esteiam a verdade absoluta. 0 lugar do psicanalista precisa ser vazio para que o paciente aconteça, exista - e isso pode dar-se através da fala ou de qualquer outra condição que o sujeito consiga criar para comunicar algo.

É lamentavelmente injusto reduzir a criação artística a um mero passatempo em detrimento ao ócio, ou a uma maneira poética de o louco se expressar. E ainda que ela circule pelo discurso do direito à cidadania e à reinserção social, que pleiteia o cuidado em oposição à cura, a arte deve ser encarada como via de acesso para sinalizar aquilo que é da ordem do real, do não simbolizado, e que serve de catapulta para encontrar um meio de inscrição mínima, que forja cisões e contrastes, e ajuda o psicótico, trabalhando com pequenos gestos e ações, a produzir atos significantes.

Como afirma Artaud (1995), a arte é uma ferramenta, um recurso para se dizer e fazer ouvir questões que a vida social impõe calar, asfixiar. Nessa proposta, o que está em jogo é o compromisso terapêutico que sempre aposta na existência de um sujeito, e que de tudo fará para oferecer 0 apaziguamento dos fenômenos invasivos e ininterruptos, mas sempre sustentando a ideia de que os pontos de estabilização e de ancoragem são compreendidos enquanto conceitos, e não como uma teoria propriamente dita. Ou seja, ambos conceitos implicam operações mais ou menos frágeis do psiquismo, possibilitando ao sujeito psicótico constituir alguma forma de endereçamento com o campo social que não seja uma relação objetal reduzida ao mero assujeitamento.

Talvez, todo segredo da psicoterapia das psicoses resida nesse dom da observação que nos permite apreender a menor modificação dos mundos parciais e suas respectivas relações. A aproximação dos fragmentos é por isso da maior importância. É possível unir, soldar partes. No entanto, ainda não sabemos se esse novo solo tem resistência suficiente (Pankow, 1989, p. 247).

Trata-se, portanto, de dispor-se a caminhar com esse sujeito - por onde quer que ele transite. Longe de ambicionar um saber pleno, a psicanálise assevera que qualquer esforço de al cançar toda a verdade está predestinado ao malogro. Na clínica das psicoses, o profissional ocupa um outro lugar, não o de sujeito do suposto saber, mas o de secretário do sujeito alienado, termo cunhado por Lacan (1985), para promover a suplência da metáfora paterna. Em outras palavras,

[...] para muitos sujeitos psicóticos, o mundo já significa coisas demais. Se tudo Ihes envia uma mensagem, talvez a última coisa que eles queiram seja outra mensagem. E se, em sua infância, as pessoas que cuidavam delem sempre sabiam demais, observando-os sem cessar, ou afirmando conhecer seus pensamentos e intenções, o clínico deve adotar, uma postura muito diferente, intervindo não de um lugar de saber e significação, mas ao contrário, de um ponto de não saber: mais como estudante do que como professor. (Leader, 2011, p. 347-348).

Se no campo da neurose, no encontro do corpo com a fala, algo desaparece, o chamado objeto a (Lacan, 2005a), na psicose, isso não se perde - e 0 efeito dessa equação é que o mundo inteiro gira ao redor do sujeito e quer algo dele, e para se proteger, ele diz: não! Ao não haver queda do objeto, se não há a falta da falta, o gozo torna-se um imperativo que invade o corpo. Nesse manejo, o lugar ocupado pelo profissional deve ser o de pequeno outro - um semelhante, que não o coloca no lugar de objeto, de dejeto, pois a identificação do psicótico a este lugar de resto, é um dos motivos que tolhe o seu posicionamento na trama do saber, e por isso, ele se defende pela recusa, pelo silenciamento. 
É preciso escutar - e suportar - aquilo que o psicótico consegue manifestar a seu turno, sem perseguir um ideal de normalização, influenciado pela própria constituição neurótica do profissional. Conforme Monachesi a presença daquele que atua na clínica das psicoses, indubitavelmente é

[...] reservada, disponível e confiável. Oferece espaço, tempo e suporte para os conteúdos e experiências que surgirem. Facilita 0 trânsito e a comunicação. [...] mantém-se neutro, ouve tudo sem preferir nada em especial, suspende seus julgamentos morais e espera 0 que está por vir. (Monachesi, 2005, p. 177).

Cabe sublinhar que o conceito de cura se circunscreve cada vez mais aos termos saída, estabilização, ancoragem, e, portanto, é forjado na ética da psicanálise que se pauta o empenho em não institucionalizar as criações artísticas, colocando-as de forma programática e engessada como parte de um tratamento, que pode estar muito mais a serviço do regozijo do técnico do que da ressignificação do sujeito através da sua reconstrução de sentidos. Os processos de expressões artísticas recobrem-se de relevância se, de fato, honrarem a subjetividade de cada sujeito: a operacionalidade reside, precisamente, no acaso, e não no a priori.Se o trabalhador da saúde mental se colocar no lugar demandante do Outro avassalador, pode provocar situações injuntivas frente às quais o sujeito responde com nova crise, justamente pela ausência de uma sustentação simbólica possível.

0 compromisso ético da psicanálise permeia o itinerário da escuta, do testemunho, e por isso vale ressaltar que os sujeitos psicóticos raramente enlaçam-se aos ideais fálicos impostos pela malha social, e quando assim 0 fazem, é pela colagem imaginária de uma relação especular mimetizadora: daí a importância de observar seus arranjos enunciativos, e quem sabe, andar ao seu lado, apostando na construção de alguma mínima posição desejante dentro de sua própria ficção.

\section{Considerações finais}

0 questionamento sobre a psicose, em sua constituição singular, sempre esteve presente no percurso acadêmico da autora, acentuado ainda mais pelo contato com uma instituição manicomial pautada pelo tradicional modelo da internação asilar - foi nesse período que a investigação de outras formas de manejo clínico, que contribuíssem para o tratamento do sofrimento e do adoecimento psíquico, se fez tão proeminente.

A prática clínica das psicoses, até os dias atuais, continua sendo acometida pelo impacto da fragilidade e, muitas vezes, da impossibilidade de confronto com as relações simbólicas. Visto que o traumático, lançado para fora do psiquismo, não obtém essa representação capaz de ligar-se a uma ideia, as palavras tornam-se reais e, é no real do corpo, que recai a experiência do sofrimento.Com essa dificuldade constantemente imposta, suscita-se outras alternativas de intervenção - articulações que possibilitem a escuta, através de estratégias que façam avivar o discurso do sujeito, buscando a (re) construção de sentidos, de possíveis cenários de existência.

Se o inventor da psicanálise buscou obstinadamente um estatuto científico para sua obra, ao mesmo tempo, ele parece nunca ter abandonado suas fontes primárias: a fiel companhia da arte, em toda sua constelação. Propor os recursos provenientes do campo artístico como um dispositivo terapêutico da psicose, parte da ideia que, no trabalho psicanalítico, por trás de algo produzido artisticamente, há sempre alguma coisa que lhe dá uma perspectiva, e, portanto, também são os ditos do sujeito. Moldar, pintar, desenhar ou falar, é tanto expor, como ocultar. Dado que a arte pode ser uma oportunidade de o sujeito dizer, ou não, de si, pode haver, obstante a uma condição mínima, um certo deslizamento da posição subjetiva, estabilizando a estrutura psicótica através de pequenas inscrições no psiquismo: se pelas criações artísticas de al guma forma o sujeito se manifesta, a posição ocupada de objeto pode, mesmo que momentaneamente, ficar em suspenso.

Mas para tanto, parece fundamental que o profissional se mantenha vigilante para não incorrer em exigências que ainda supostamente bem-intencionadas, acabem por mostrar-se em demasia. Sem ocupar um lugar de autoridade ou de especialista, o técnico precisa reconhecer que cada tratamento é único e não uma adaptação aos preceitos convencionais. Impor o recurso da arte como uma atividade obrigatória, sem que haja interesse do indivíduo, com tentativas ortopédicas de, forçosamente, querer dar ao sujeito uma significação, seria potencializar ainda mais a demanda do Outro para 0 psicótico, que seguiria sentindo-se invadido e tomado no lugar objetal: com o excesso de presença, a recusa continuaria sendo a melhor defesa.

Tal como na neurose ou na perversão, também a psicose demanda uma clínica que não faz calar o sujeito, pelo contrário, se propõe a escutar as construções delirantes, sem eliminar as produções sintomáticas. Seu contraponto é frente ao modelo normativo: é sempre a ética da psicanálise que sustenta todas as práticas, pois não silencia as diferenças na busca hegemônica do padrão dominante - o psicanalista faz função testemunhal, acompanhando, artesanalmente, a edificação de algo socialmente viável, sem apresentar receitas definitivas. Éuma aposta na particularidade de existência de um sujeito, quem quer que este seja.

A aproximação entre a arte e a psicanálise e a psicose precisam ser tomadas para além de um arranjo de complementariedade: estes campos fazem vizinhança, entretanto, não se trata de algo contínuo e que ocorra em todas as suas extensões. Encontrar no ato criativo, na produção de uma obra que faça suplência ao arranjo estrutural, é ofertar um dispositivo para a estabilização psicótica. E a potência da psicanálise, ao incitar aberturas e fechamentos, provoca descontinuidades, irrupções nos fluxos errantes, viabilizando a esses sujeitos outras alternativas de ser e estar no mundo, outras tramas e tessituras no enlaçamento social.

Chegado ao fim dessa pesquisa, elaborar uma conclusão é sempre 0 momento mais inquieto da produção de uma escrita - de maneira paradoxal, parece ser a fatia mais inconcludente, uma vez que se abrem novos enigmas quando se cai no engodo de se ter conseguido responder plenamente ao primeiro problema. A autora, enquanto sujeito desejante, arriscou-se, na dimensão subjetiva da escrita, denunciar, pela grafia, as suas insuficiências e instabilidades: no transcorrer dessas páginas, quiçá haja ideias ainda a serem desdobradas neste ou em outros lugares, para que o assunto não se encerre: a psicanálise, enquanto corpo teórico vivo, sempre se deixa interrogar.

Alguns pontos foram modestamente observados, com a ousadia de quem ousa ensaiar a cartografia de um mapa, talvez para utilização pessoal futura da autora. Por hora, fica-se com as sementes plantadas em um terreno, hipoteticamente, fertilizado. Fora isso, nada mais pode-se concluir, pois, assim como a arte e a psicanálise e a psicose foram aqui propostas enquanto lugares que se conversam, se freqüentam e não se esgotam em si, assim como as considerações finais aqui descritas, que mais compactuam com sinal de reticências do que com ponto final. 


\section{Referências}

Artaud, A. (1995). Linguagem e vida. São Paulo: Perspectiva.

Balbo, G.\& Berges, J. (2003). Há um infantil da psicose? Porto Alegre: CMC.

Calligaris, C. (1989). Introdução a uma clínica diferencial das psicoses. Porto Alegre: Artes Médicas.

Calligaris, C. (2004). Cartas a um Jovem terapeuta. São Paulo: Alegro.

Coriat, E. (1997). Psicanálise e clínica de bebês. Porto Alegre: Arte de Ofícios.

Descartes, R. (2001). Discurso do método. 2. ed. São Paulo: Martins Fontes.

Dolto, F. (1984). No jogo do desejo. Rio de Janeiro: Zahar.

Ferreira, C. M. R.; Trópia, M. R. A. B. (2000). 0 escriturário das suplências. Curinga, Belo Horizonte, n. 14, p. 144-149.

Freud, S. (1969a). Escritores criativos e devaneios. Edição standard brasileira das obras psicológicas completas. vol. 9. Rio de Janeiro: Imago.

Freud, S. (1969b). Neurose e Psicose. Edição standard brasileira das obras psicológicas completas. vol. 19. Rio de Janeiro: Imago.

Freud, S. (1969c). Uma dificuldade no caminho da Psicanálise. Edição standard brasileira das obras psicológicas completas. vol. 17. Rio de Janeiro: Imago.

Goidanich, M. (2004). Prisioneiros da passagem. A clínica psicanalítica como potencializadora do trabalho com psicóticos na saúde pública. Dissertação (Mestrado em Psicologia Social e Institucional) - Instituto de Psicologia, Universidade Federal do Rio Grande do Sul. Porto Alegre, p. 144.

Guerra, A. M. C. et al. (2006). A função da obra na estabilização psicótica: análise do caso do Profeta Gentileza. Interações, São Paulo, v. 11, n. 21, p. $29-56$.

Lacan, J. (1964). O Seminário, Livro 11: os quatro conceitos fundamentais da psicanálise. Rio de Janeiro: Jorge Zahar.

Lacan, J. (1984). O Seminário, Livro 1: os escritos técnicos de Freud. Rio de Janeiro: Jorge Zahar Editor.

Lacan, J. (1985). O Seminário, Livro 3: as psicoses. Rio de Janeiro: Jorge Zahar. Lacan, J. (1992). O Seminário, Livro 8: a transferência. Rio de Janeiro: Zahar.

Lacan, J. (1997). O Seminário, Livro 7 :a ética da psicanálise. Rio de Janeiro: Jorge Zahar.

Lacan, J. (1998). A instância da letra no inconsciente ou a razão desde Freud. Rio de Janeiro: Jorge Zahar.

Lacan, J. (2005a). O Seminário, Livro 10: a angústia. Rio de Janeiro: Jorge Zahar.

Lacan, J. (2005b). O Seminário, Livro 23: 0 sinthoma. Rio de Janeiro: Jorge Zahar.

Lacet, C. (2004). Da foraclusão do Nome-do-Pai à foraclusão generalizada:considerações sobre a teoria das psicoses em Lacan. Psicologia USP, São Paulo, v. 15, n. 1, p. 243-262.

Leader, D. (2011). 0 que é loucura: delírio e sanidade na vida cotidiana. Rio de Janeiro: Jorge Zahar.

Leite, M. P. S. (2007). Psicanálise Lacaniana: cinco seminários para analistas kleinianos. São Paulo: Iluminuras.

Lima, E. F. A. (2009). Arte, clínica eloucura: territórios em mutação. São Paulo: Summus editorial/FAPESP.

Lispector, C. (1980). Água viva. Rio de Janeiro: Nova Fronteira.

Mannoni, M. (1999). A criança, sua doença e os outros. São Paulo: Via Lettera.

Melman, C. (1991). Estrutura lacaniana das psicoses. Porto Alegre: Artes Médicas.

Monachesi, A. R. O lugar do psicanalista em uma clínica das psicoses:al gumas reflexões. Psyche, São Paulo. 9, n. 16, p. 165-182, 2005.

Morais, M. B. L. (2006). Poesia, psicanálise e ato criativo: uma travessia poética. Estudos de Psicanálise. Belo Horizonte, n. 29, p. 45-56.

Neubarth, B. E. (2009). No final da linha do bonde um tapete voa-dor: a oficina de criatividade do hospital São Pedro (1990-2008): inventário de uma práxis. Tese (Doutorado em Educação) Instituto de Educação, Universidade Federal do Rio Grande do Sul. Porto Alegre, p. 289.
Pankow, G. (1989). O homem e sua psicose. Campinas: Papirus.

Quinet, A. (2006). Teoria e clínica da psicose. 3. ed. Rio de Janeiro: Forense Universitária.

Ravasio, M. T. H. (2016). Considerações sobre a pesquisa em psicanálise. Salão do Conhecimento UNIJUI.Recuperado https://www.publicacoeseventos. unijui.edu.br/index.php/salaoconhecimento/article/view/7016.

Read, H. (1983). Arte e alienação. Rio de Janeiro: Zahar.

Roudinesco, E. e Plon, M. (1998). Dicionário de psicanálise. Rio de Janeiro: Jorge Zahar.

Silva, T. J. F. \& Alencar, M. L. O. A. (2009). Invenção e endereçamento na oficina terapêutica em um centro de atenção diária. Revista Latinoamericana de Psicopatologia Fundamental. São Paulo, v. 12, n. 3, p. 524-538.

Silva, L.B.C. (2001). Doença mental, psicose e loucura: representações e práticas da equipe multiprofissional de um hospital dia.São Paulo: Casa do Psicólogo.

Souza, E. L. A. (2014). A transgressão que salva. Revista Latinoamericana de Psicopatologia Fundamental. São Paulo, v. 17, n. 3, p. 787-796.

Winnicott, D. W. (1975). O brincar e a realidade. Rio de Janeiro: Imago.

Winnicott, D.W. (1983). O ambiente e os processos de maturação: estudos sobre a teoria do desenvolvimento emocional. Porto Alegre: Artmed. 